\title{
Brand governance practices in Canadian national sport organizations: An exploratory study
}

\author{
Marijke Taks (PhD) (Corresponding author) \\ School of Human Kinetics, University of Ottawa \\ 125 University Private \\ Ottawa, ON K1N 6N5 Canada \\ Tel: +1 (613) 562-5800 (ext. 2453) \\ marijke.taks@uottawa.ca \\ Benoit Seguin, $\mathrm{PhD}$ \\ School of Human Kinetics, University of Ottawa \\ 125 University Private \\ Ottawa, ON K1N 6N5 Canada \\ Tel: +1 (613) 562-5800 (ext. 4305) \\ bseguin@uottawa.ca \\ Michael L. Naraine, PhD \\ Department of Management, Deakin Univeristy \\ 70 Elgar Road \\ Burwood, Victoria, Australia \\ 3125 \\ Tel: +61 (3) 92468772 \\ michael.naraine@deakin.edu.au \\ Ashley Thompson, M.A. \\ School of Human Kinetics, University of Ottawa \\ 125 University Private \\ Ottawa, ON K1N 6N5 Canada \\ Tel: +1 (613) 562-5800 (ext. 7270) \\ athom156@uottawa.ca \\ Milena M. Parent, PhD \\ School of Human Kinetics, University of Ottawa \\ 125 University Private \\ Ottawa, ON K1N 6N5 Canada \\ Tel: +1 (613) 562-5800 (ext. 2984) \\ milena.parent@uottawa.ca \\ Russell Hoye, $\mathrm{PhD}$ \\ Office of the Deputy Vice-Chancellor Research \\ La Trobe University \\ 1 Kingsbury Drive \\ Bundoora 3086, Australia \\ Tel +61 394791345 \\ r.hoye@latrobe.edu.au
}




\title{
Brand governance practices in Canadian national sport organizations: An exploratory study
}

\begin{abstract}
Research Questions: We explored if and how decision-makers of different types of national sport organizations (NSOs) govern their brand, considering the changing landscape and the role of stakeholders and social media. The three research questions were: (RQ1) Do leaders of NSOs include brand governance in their overall governance?; (RQ2) How important is the relationship between the NSOs and their stakeholders for NSOs' brand governance?; (RQ3) How does social media contribute to NSOs' brand governance?
\end{abstract}

Research methods: Thirty-two chief executive officers (CEOs) and/or board members of 58 Canadian NSOs $(\mathrm{RR}=55 \%)$ participated in an online survey. Data were collected about brand governance in the organization (8 questions), the interrelationship with stakeholders (4 questions), and the role of social media in brand governance (4 questions).

Results and findings: Brand governance is absent in small NSOs, and in early stages of application by larger NSOs. NSOs deal with their brand primarily internally, with no operational involvement of stakeholders, missing opportunities for possible knowledge transfer and co-creation to help NSOs govern their brand. Social media is a cost-efficient way to brand the organization, but a lack of control and consistency indicates a need for brand governance related to social media.

Implications: NSOs would benefit from actively involving stakeholders to co-create and strengthen their brand. Social media offers opportunities for branding, but governance regulations should help overcome major challenges. Future research should include 
interviews with NSOs' decision-makers to further understand how NSOs can engage more meaningfully with stakeholders and social media to strengthen their brand governance.

Keywords: co-creation, online survey, social media, stakeholders, organizational taxonomy. 


\section{Brand governance practices in Canadian national sport organizations: An exploratory}

\section{study}

In the past 30 years, sport governing bodies in Western societies have been exposed to political, social, ethical, regulatory, and technological forces in society. Moreover, stakeholders have become more important and involved in national sport organizations (NSOs; Parent, Naraine, \& Hoye, 2018). To keep up with these trends, NSOs have been pushed to higher levels of professionalism and performance (Lang et al., 2018). Particularly, the implementation of the Canadian Non-Profit Act in 2011(Canada Not-for-profit Corporations Act, 2009) has forced all non-profit organizations, including Canadian NSOs, to regulate their governance practices by 2017. For instance, boards are required to be governance boards, thinking long term, and strategically. A recent report published by Deloitte found Canadian NSOs are deficient in two key areas of business: branding and marketing (Krashinsky, 2015). Consequently, the Canadian Olympic Committee (COC) invested into an NSO enhancement initiative with the goal of improving NSOs' business operations. This has led to some NSOs (e.g., Swimming Canada, Curling Canada) rebranding themselves in the hopes of strengthening their position in the market, given that their viability heavily depends on various stakeholders (Krashinsky, 2015). These traditional brand management practices (i.e., managing brands, creating new logos, branding campaigns) at the functional/operational levels (e.g. marketing director) are still important (Zaichkowsky, 2015), but are no longer sufficient given the changing landscape and the important role of stakeholders and social media. As such, there is a need to explore brand governance practices at the top/strategic level of the organisation; that is, to what extent decision-makers of different types of NSOs have started to implement brand governance 
practices for strategic purposes, and whether leaders consider the interrelationship with stakeholders and the role of social media in this process.

Brand governance refers to "a system of building a brand that is guided by the vision, mission and values of an organization and that systematically nurtures a brand value to become and remain a long-term strategic asset” (Séguin \& Abeza, 2019, p. 368). It can be understood as a system of rules, practices, and processes, directed and controlled through clear, actionable goals to establish and sustain an entity's long-term brand value (Séguin \& Abeza, 2019).

Stakeholders can be strategic partners in NSO brand governance (Ferkins \& Shilbury, 2015a), as NSOs can capitalize on stakeholders' expertise to help them co-create and govern their brand. Social media can serve as a vehicle to achieve strategic brand objectives (Sanderson \& Yandle, 2015), if social media is well developed and properly managed (Naraine \& Parent, 2017a, 2017b). This relationship between brand governance, stakeholders and social media has yet to be explored amongst NSOs. Moreover, previous research has demonstrated that the ability of NSOs to adapt to changing environments may vary according to the available resources within NSOs, such as human and financial resources (Kikulis, Slack, \& Hinings, 1995a, 1995b). Thus, the purpose of this paper is to examine how decision-makers (board members and CEOs) of different types of NSOs (in terms of available resources) govern their brand, considering the important role of stakeholders and social media. The specific research questions are: (RQ1) Do leaders of NSOs include brand governance in their overall governance?; (RQ2) How important is the relationship between the NSOs and their stakeholders for NSOs' brand governance?; (RQ3) How does social media contribute to NSOs' brand governance?

\section{Literature Review and Theoretical Framework}

\section{Brand Governance in NSOs}


Studies on sport organization governance have typically addressed organizational aspects such as board composition, representation and management, and power (Hoye \& Cuskelly, 2003a, 2003b), leadership (e.g., Inglis, 1997), conflict (e.g., Hamm-Kerwin \& Doherty, 2010), and strategic capability (e.g., Ferkins \& Shilbury, 2010, 2015a, 2015b), but little has been done related to brand governance. The importance of branding and having a strong brand to the success of a company is well recognized in the literature. It has been suggested that brands are primary sources of a company's value and as such can be considered its most valuable assets (Helm \& Jones, 2010). Consequently, companies spend considerable sums of money and time to launch new brands and leverage existing ones to gain competitive advantages (Kumar, 2003). Most research to date on branding in sport organizations has focussed on brand management in the context of collegiate athletics (Gladden, Milne, \& Sutton, 1998), professional sport teams (Gladden \& Funk, 2002; Gladden \& Milne, 1999; Richelieu, 2004; Underwood, Bond, \& Baer, 2001; Watkins, 2014) or sport events (Séguin, Richelieu, \& O’Reilly, 2008). This past work concentrated on studying brand-related concepts such as image, loyalty, associations, brand equity, and the operational side of branding; that is, how to understand, manage, and protect a sport brand, tasks essentially performed by marketing people. This operational and strategic brand management is an internal activity of the organizations and remains important in creating brand equity. However, while brand equity is “increasingly seen as critical to an organization's future value creation ability" (Helms \& Jones, 2010, p. 547), it is also at an increased risk of being damaged given that "the potential hazards inherent in managing brands and brand experience multiply" (p.547). Such threats can be found within a fast-changing world that incudes, for example, a networked society, more empowered consumers, stronger interactions with stakeholders, a growing number of distribution and communication touchpoints, and the 
risks associated with using social media (Helms \& Jones, 2010). All these threats can dilute customers' experiences with the brand, its consistency and ultimately its equity. Thus, scholars such as Hatch and Schultz (2010), Helms and Jones (2010), and Ind and Bjerke (2007) proposed the concept of brand governance as a new approach to brand management. As such, sport organization's strategic brand management should be based on visionary brand governance, which is externally focused. Brand governance is expected to be a responsibility of the top level of an organization (Board of Directors, CEOs), and goes beyond simply maintaining brand identity elements, such as the name, logo, font type, symbols, colour, or shape, which are usually the responsibility of mid-level management (Zaichkowsky, 2010). Thus, we posit that NSOs would benefit from thinking long term, and strategically about brand governance, and explore whether leaders of NSOs implement and apply brand governance in their organizations. Although Canadian NSOs do not enjoy the same exposure as many professional sport teams such as New York Yankees (Bauer, Sauer, \& Schmitt, 2005; Richelieu \& Pons, 2009) or events such as Olympic Games (Ferrand, Chappelet, \& Séguin, 2012) with their global brands, building a strong brand, managing it and being good at governing their brand, is equally important for NSOs to strengthen their image and reputation, as well as foster emotional ties with their stakeholders. For instance, NSOs rely on government agencies, members, spectators, and sponsors for their resources, be it federal funding, member buy-in to the 'cause', or corporate support. Hence, there is a need for well thought out rules, practices, processes, and actionable goals to establish and sustain NSOs' long-term brand value, which surpasses the notion of just 'managing the brand'. Thus, we shift the focus from traditional brand management (i.e., logo development and implementation) and strategic brand management (i.e., building, measuring and managing brand equity) which are internal activities, to brand governance (Séguin \& Abeza, 
2019) which is an externally oriented activity. We explore if, and how NSOs govern their brand, and consider the importance of stakeholders and social media for NSO's leaders when making decisions, and/or taking actions in this process.

\section{Brand Governance and the Relationship between NSOs and Stakeholders}

Stakeholder participation is one of four basic principles of good democratic governance (Parent, 2016). Parent et al. (2018) found Canadian NSOs to have an increasingly similar set of stakeholders, namely paid staff, volunteers, federal government, suppliers, the COC, athletes and their entourage, coaches, Own the Podium, fans, print and social media, Canadian Centre for Ethics in Sport, and international, national and local sponsors. As internal and external stakeholders are believed to play a crucial role in co-creating a brand (Ferrand et al., 2012; Jones, 2005) and possibly impact a brand's current and long-term's equity (Ind \& Bjerke, 2007), the engagement of stakeholders with an organization's brand must be carefully managed.

Parent and Séguin (2008) identified the importance of leadership groups for branding. Leaders establish the organization's vision early in the brand-building process (Harris \& de Chernatony, 2001), as they are responsible for important decisions including the logo, slogan, and colors. While internal employees are engaged in this process, external stakeholders also feature into the brand building and value creation process (Hatch \& Schultz, 1997; Kowalcyk \& Pawlish, 2002; MacIntosh \& Doherty, 2007; Schultz \& Ervolder, 1998). Primary stakeholders have a greater tendency to influence NSOs, including their brand governance, compared to stakeholders who are less important, and not so critical for survival (i.e., secondary stakeholders; Clarkson, 1995; Parent et al., 2018).

A framework applied by Parent, Eskerud, and Handstad (2012) in studying brand creation in the context of recurring sports events revealed the leadership, context, and nature of the event 
as key components of the branding process. Two other factors were found to impact the brand creating process: (1) the importance of the organization's core values as a key antecedent, which guide the leaders' actions and behaviours; and (2) the institutional affiliation with the respective sport organizations as key stakeholders. The organization's core values are recognized as essential characteristics that define its brand (Hutchinson \& Bennett, 2012; Urde, 2003) and as such, can serve as guiding principles and inspirations to the brand building process (Urde, 2003). From a branding perspective, Urde (2003) defined core values as "overarching concepts and allembracing terms that summarize organizational brand identity and serve as guiding principles for the brand building process" (as cited in Hutchinson \& Bennett, 2012, p. 436). Given the importance of stakeholders in co-creating the brand (Hatch \& Schultz, 2010; Helm \& Jones, 2010), it is essential that core values are met with commitment and consistency, as failure to do so will undermine the credibility of an organization's brand (Hutchinson \& Bennett, 2012; Ind, 2007). Helm and Jones (2010) stated the following:

the firms' ability to create long-term value appears to come not only from ownership of a brand that holds out the offer of a distinctive and meaningful experience to consumers and other stakeholders, but also from being able to consistently deliver that experience so as to engage and build long-term relationships with them. (p. 580)

As mentioned earlier, through co-creation, a firm is able to create and preserve long-term value and brand equity (Helm \& Jones, 2010), hence the importance to engage all stakeholders (i.e., beyond members, fans) contributing to the brand equity process (Ferrand \& McCarthy, 2009; Jones, 2005), as they may be influential in creating additional value (Merz, He, \& Vargo, 2009; Vargo \& Lusch, 2004). This approach is consistent with Iglesias, Ind, and Alfaro (2013) who posit that the branding literature has converged to a stakeholder-focus brand era (Merz et al, 
2009), where brands are social processes in which multiple stakeholders are involved in the cocreation of brand value. Consequently, the ways in which stakeholders participate in the cocreation of brand value is a governance issue for organizations.

\section{Brand Governance, NSOs and Social Media}

Given that brand governance is externally focused, and brand management is internal, a logical next step is to consider social media as an externally-focused activity. The newest characteristic in the brand discourse is social media. Various sport properties have identified the value proposition of social media, specifically the ability to create a direct, ongoing link to their consumers (Sanderson \& Yandle, 2015). Thompson, Martin, Gee, and Geurin (2017) have even suggested that sport properties are exhibiting elements of brand anthropomorphism via social media, ostensibly donning a sentient form. Indeed, social media can serve as a powerful marketing communications tool, especially for those organizations with limited exposure (e.g., NSOs). However, there is still much to uncover about social media and NSOs in the current landscape, notably if and how it is used in the brand governance process.

While NSOs have experience in virtualizing themselves and developing relationships in an online space (see Girginov et al., 2009), the ferocity with which social media has pervaded the sport industry has simultaneously been a challenge and opportunity for NSOs. Notably, a slate of inquiry by Naraine and Parent (2016a, 2016b, 2017a, 2017b) sought to understand NSOs and social media more intimately. One study in particular revealed these sport organizations embraced social media to demonstrate relevancy, keep stakeholders updated, and connect to new groups (Naraine \& Parent, 2017a). However, NSOs have been known to simply communicate results and scores (Naraine \& Parent, 2016a) and have been unable to amplify their brand messaging (Naraine \& Parent, 2016b), suggesting a lack of strategic planning and foresight 
(Naraine \& Parent, 2017b). Thus, it is unclear the extent to which social media is being utilized to communicate specific elements such as an NSOs mission, vision, and values. Moreover, it remains unknown whether social media is actually considered important by these organizations (from the perception of senior managers and directors, not marketing communications staff), and the overall impact this tool has or can have on their brand, and how it affects NSOs brand governance.

\section{Brand Governance and Different Types of NSOs}

Brand governance is likely to be different according to the NSOs' organizational capacity. Slack and Hinings $(1992,1994)$ identified variations in Canadian NSOs'capabilities based on human, financial, and physical resources (Hall et al., 2003). These variations denoted different levels of professionalization. There are, of course, many more variables to differentiate between levels of professionalization of NSOs (e.g., Clausen et al., 2018; Winand, Vos, Claessens, Thibaut, \& Scheerder, 2014). Lang and colleagues (2018) stated that: "more highly professionalized types of NSFs are characterized by larger size and considerable financial resources, while less professionalized types may show contrary organizational characteristics" (p. 303), but came to the conclusion that the common perception "the larger, the more financial resources, the more professionalized" (p. 311) it is not necessarily the case. Instead, the authors found that size was more aligned with formalization and financial resources with paid staff. However, it should be noted that size in their study was measured based on the number of members in the NSOs, and not based on paid staff.

Given the exploratory nature of this contribution, we built on Slack and Hinings's foundational work on Canadian NSOs, and consider the number of paid staff and the annual budget as drivers of organizational capacity an capabilities. Seippel (2002) noted that 
organizations with a higher level of paid staff tend to be larger. Bayle and Robinson's (2007) posited that financial income affects the performance of an organization. Hence, it is expected that variations in resources, such as FTE's (in terms of paid staff) and financial resources (in terms of size of the budget) affect NSOs` organizational capacity, and consequently their ability to handle brand governance (or not). For instance, it can be assumed that brand governance is more challenging for smaller NSOs, compared to larger NSOs, due to fewer resources. Therefore, we explore if and how different types of NSOs, based on their size (informed by human and finacial resources), adopt brand governance principles.

\section{Theoretical Framework}

Brand governance is about building and nurturing the brand value based on the organization's mission, vision, and values (Séguin \& Abeza, 2019). The authors argue, that a visionary brand approach is necessary to preserve the consistency and cohreance of the brand. This goes beyond strategic brand management and involves stakeholders in the co-creation (Ferrand et al., 2012) and governance of the brand (Séguin \& Abeza, 2019).

The governance structure of a brand is composed of three interconnected systems including brand governance, strategic brand management and operational brand management (see Séguin \& Abeza, 2019). The first system, brand governance, consists of a systematic approach for building and nurturing a brand as a long term strategic asset. This is built on "the vision, mission and values of an organization, developed through long-term policies and governed by processes such as integrity and transparency” (Séguin \& Abeza, 2019, p. 374). Hence, the need to understand the importance of brand governance for NSOs, to align the brand with the NSOs' mission, vision and values, perform brand research, develop policies, create documents, understand at which levels the decisions related to brand governance take place, and 
investigate what factors affect the brand governance process, including at which levels these processes are being discussed, and to what extent the image and reputation of the NSO - as important brand components (Keller, 2003) - are considered when making brand decisions.

Since stakeholders play a crucial role in co-creating the brand, their involvement in the development of brand governance long-term policies and processes is anticipated. These policies and processes are the guiding principles of the second system which consists of the strategic management of the brand. This system is mainly concerned about developing internal capabilities to develop, manage and measure brand equity. Finally, the long-term focus of brand governance policies and strategic brand management capabilities allow for the consistent delivery of the brand which consists of the third system, the operational brand management. In this system, stakeholders play an important role as they activate the brand within their own communications channels. Hence the importance of having an open and transparent relationships with stakeholders.

As Freeman (1984) argued, the relationship between organizations and stakeholders is bilateral, meaning organizations can influence stakeholders, but can also be affected by these actors, and vice versa. These stakeholder inter-relationships influence governance (Ferkins \& Shilbury, 2015b; Parent et al., 2018), including, brand governance. However, this interrelationship has yet to be empirically examined in the context of brand governance. Given the unknown territory on the inter-relationship between NSOs and stakeholders as it pertains to brand governance, the way in which NSO leaders communicate with stakeholders needs to be explored, and if NSOs expose their mission, vision, and values, as key components of an organization's identity and brand (Bouchet, Hillairet, \& Bodet, 2013) through their 
communication with the stakeholders. In turn, stakeholders may also affect (i.e., influence or be involved with) NSOs' brand.

As Kietzmann, Hermkens, McCarthy, and Silvestre (2011) pointed out, social media involves conversing, sharing, and grouping between stakeholders in an online setting. To uncover the role of social media in NSOs brand governance process, the importance of social media for NSOs needs to be understood, and to what extent mission, vision, and values are communicated through social media. Reversely, social media may impact NSOs brand governance.

Brand governance practices in NSOs, the interrelationship with stakeholders and the role of social media in this process presented in figure 1 . The three research questions that quide the research are: (RQ1) Do leaders of NSOs include brand governance in their overall governance?; (RQ2) How important is the relationship between the NSOs and their stakeholders for NSOs' brand governance? and (RQ3) How does social media contribute to NSOs' brand governance? Acknowledging that brand governance may be substantially different accoding to NSOs' organizational capacity, the model is analyzed for NSOs of different sizes.

[INSERT FIGURE 1 ABOUT HERE]

\section{Method}

\section{Sample}

All 58 NSOs that are listed on the Sport Canada website were invited to participate in the study. Of those, CEOs and/or board members of 32 NSOs responded to an online survey (response rate $=55 \%$ ). For seven of the $32 \mathrm{NSOs}$, both the CEO and board member of the same NSO responded. This allowed to compare information and responses between them as well as with organizational documents. When organizational documents were not available to validate 
differences in responses, the response from the decision-maker with the highest seniority in the NSO was retained, expecting a more thorough knowledge of the NSOs governance. The 32 NSOs were categorized in four groups, based on budget and full-time personnel, similar to the segmentation protocol used by the COC's 2013 audit on NSOs (COC, 2013). The categories were adapted to reflect the current realities of personnel and budget. The four segments were: (1) small ( $\mathrm{n}=7),(2)$ medium sized $(\mathrm{n}=15),(3)$ large $(\mathrm{n}=8)$, and (4) very large $(\mathrm{n}=2)$. Small NSOs were defined as NSOs with less than five employees and a budget below $\$ 1$ million CAD (e.g., the Canadian Weightlifting Federation). Medium-sized NSOs employed between five and 20 people and carry a budget between $\$ 1$ million and $\$ 4.5$ million CAD (e.g., Squash Canada). Large NSOs employed between 21 and 50 people and carry a budget between $\$ 4.5$ million and under $\$ 20$ million CAD (e.g., the Canadian Snowboard Federation). Rugby Canada and Curling Canada were two outliers (i.e., very large NSOs) with 64 and 53 employees respectively, and budgets of \$21.5 million CAD and \$24 million CAD respectively.

\section{Survey and Measurements}

Interviews with members of the target population served as a first pilot study (Parent et al., 2018) from which the survey was developed, along with relevant literature. Content validity was further established based on expert evaluation of all reserach team members. After ethics approval, the survey was pilot tested with a member of the target population. Any wording issues were adjusted based on this member's suggestions, so participants understood the meaning. Further more, all study participants had the chance to contact the research team at any point for clarification ${ }^{1}$. The survey was developed, both in English and in French, with phrasing specific to the Canadian NSO population.

\footnotetext{
${ }^{1}$ Only one participant did, but not for any of the questions considered in this manuscript.
} 
A recruitment e-mail was sent out to all 58 NSOs in the fall of 2017, indicating the purpose of the study, and asking to identify a board member who would be best positioned to participate in the survey, in addition to the CEO. When positive responses were received, another e-mail was sent out to the CEO and the identified board member with a link to the online survey. Two reminder e-mails were sent out to those NSOs that had yet to respond. Data were collected until March 2018. The survey ${ }^{2}$ collected information on brand governance within the organization, the interrelationship between NSOs brand governance and stakeholders, and the role of social media in NSOs brand governance.

Brand governance within the organization (eight questions). The importance of branding for the NSOs was tested by asking: "To what extent do you feel brand/branding is an important issue today for national sport federations/organizations?" (measured on a 5-point Likert scale, from $1=$ not at all to $5=$ very important). Furthermore, NSOs were asked if their brand was in line with organization's vision, mission, and values; whether NSOs had conducted research on their organization's brand, possessed an official brand document, developed brand policies/regulations/guidelines (two categories: yes/no measures). It was also asked to identify who's responsibility it is to make brand management decisions (four categories: CEO/Executive director, Board of Directors, marketing team, other), and at which level is brand strategy discussed (two categories: internal - Board of Directors or committees; external stakeholders). The influence of the NSO's brand on the internal performance was asked by the following question: "To what extent is the organization's image and/or reputation considered when

\footnotetext{
${ }^{2}$ The survey as a whole transcended brand governance and included: (1) baseline information of the NSOs (e.g., number of staff and budget); (2) governance and stakeholder relationships (e.g., communication with stakeholders and accountability); and, (3) branding and social media. It took about one hour to complete. This contribution reports on the brand governance section.
} 
operational decisions and actions are made/performed?" (measured on a 5-point Likert scale, $1=$ not at all to $5=$ always).

Interrelationship between NSOs' brand governance and stakeholders (nine questions).

Four questions were specifically related to brand governance and tested the interelationships in two directions, from NSO to stakeholders and from stakeholders to NSO. First, we asked if NSOs communicated differently with different stakeholders (two categories: yes/no measures) and whether their current stakeholder communication fitted with their organization's mission, vision, and values (measured on a 5 -point Likert scale, $1=$ not at all to $5=$ always). Second, we asked to what extent stakeholders influenced, or were involved with the management of the NSOs brand (measured on a 5-point Likert scale, $1=$ not at all to 5= always).

Role of social media in NSOs' brand governance (four questions). Three questions explored the role of social media in brand governance of NSOs: (1)" To what extent do you feel social media is an important issue today for national sport federations/organizations?”, (2) “To what extent does your organization use social media to specifically communicate your organization's mission, vision, values, and goals?" , and (3) "To what extent does social media communication impact your organization's brand?" (measured on a 5-point Likert scale ranging from $1=$ not at all to $5=$ always/very important). The fourth question asked to name three strengths and three challenges related to governing their brand using social media.

\section{Data analysis}

Descriptive statistics were used to analyze the data. Significant differences between the four types of NSOs were tested by calculating ANOVAS for the ordinal scale variables. Post-hoc Tukey tests were applied to test for significant differences between the groups. Chi-square

\footnotetext{
${ }^{3}$ Given the exploratory nature of the study, we did not elaborate on the different types of social media as it pertained to brand governance. In generic terms, we refer to Facebook, Instagram, and Twitter (e.g., Narraine \& Karg, 2019).
} 
analysis (for categorical variables) could not be performed because of multiple cells with frequencies below $\mathrm{n}=5$.

\section{Results}

\section{Brand governance within the organization (Table 1)}

Overall, brand is an important issue for all NSOs, but particularly for the medium and large NSOs. NSOs' brand is in line with their mission, vision, values, and goals, especially for medium and larger NSOs. Brand research, brand documents, and brand policies and regulations are pretty much non-existent in small NSOs, which may be due to limited resources. All other types of NSOs have performed some kind of brand research, be it internally or through consulting firms. This supports the fact that brand is important for their organization. We see some progression according to the size of NSOs when it comes to having brand documents, policies, and regulations. Having something in writing which explicitly talks about the brand demonstrates a more sophisticated level of brand governance as the NSOs get larger.

In small NSOs, brand management decisions are mainly taken at the level of the Board of Directors. In contrasts, in medium, large, and very large NSOs, the decision-making process about brand management is done at the senior executive level (i.e., CEO or Executive Director). The fact these decisions are taken at the senior management level (as opposed to mid-level management) may suggest that brand is of strategic importance. However, this can also be due merely to larger NSOs actually having the available organizational resources to do so. Brand strategy is discussed internally by all NSOs while medium and large NSOs are more likely to seek input from external stakeholders (about 2/3).

There are significant differences amongst NSOs regarding the importance of image and/or reputation when making operational decisions and/or taking actions. Small NSOs do what 
they have to do, without strong consideration for their image and reputation. Medium, large, and especially very large NSOs are much more conscious as to how they are being perceived externally in the way they conduct their business.

[INSERT TABLE 1 ABOUT HERE]

\section{Interrelationship between NSOs brand governance and stakeholders (Table 2)}

Almost all NSOs, regardless of size, indicated that they communicate in a variety of ways with their stakeholders. The way in which medium-sized, the large and very large NSOs communicate with their stakeholders fits well with the NSOs' mission, vision, and values (average score $>4$ on a 5-point Likert scale). This is important as it reflects the core identity of the NSOs. It demonstrates that larger NSOs want to make sure their communication is consistent with who they say they are.

The level of stakeholder involvement with brand management was relatively low for all NSOs. However, medium-sized NSOs reported a significant higher level of stakeholders' influence in brand management $(M=3.53, S D=0.64 ; \mathrm{p}<.05)$. Large NSOs showed an average influence score of $M=3.25(S D=0.71)$, but very large and small NSOs show low averages of $M=2.50(S D=0.71)$ and $M=2.29(S D=1.11, \mathrm{p}<.05)$ respectively, indicating that they feel that the influence of stakeholders on their brand management is quite limited.

\section{[INSERT TABLE 2 ABOUT HERE]}

\section{Role of social media in brand governance (Table 3)}

Social media is an important issue for all types of NSOs (all averages $>4$ on a Likert scale from $1=$ not at all to $5=$ very important, and relatively small standard deviations). Mediumsized and large NSOs show some tendency to communicate about their mission, vision, values, and goals through social media ( $M=3.73$ and $M=3.88$, respectively on a 5-point Likert scale). 
This is less the case for very large NSOs $(M=3.00)$ and small NSOs $(M=2.86)$, indicating they tend not to use social media in this more governance focused manner (it is more about promoting their events and themselves). Except for small NSOs, other types of NSOs confirmed social media communication impacts their brand, with again medium-sized NSOs standing out with a significantly higher average $(M=4.40, S D=0.63, \mathrm{p}<.05)$.

\section{[INSERT TABLE 3 ABOUT HERE]}

When asked to identify three strengths and three challenges related to governing their brand using social media, NSOs revealed, not surprisingly, the following strengths: (1) connectivity, (2) control, and (3) effectiveness; the three challenges were: (1) negative brand impact, (2) consistency, and (3) control. Connectivity contributes to raising the brand awareness and associations through the ability to reach out to people all over the world, but lack of consistency remains a challenge in general, but also from a brand governance standpoint.

NSOs control the message, which is in line with the fact that they like to manage the brand internally, but interestingly the challenge also lies in the risk of losing control; for example, retweets of other stakeholders (athletes, volunteers, etc.), may affect their brand negatively. Social media is a cost-efficient way for branding the organization, but consistency can be problematic, especially for very large NSOs which host multiple events. These multiple events have multiple brands, to the point they can become very confusing and challenging to manage. The negative brand impact, difficulty with consistency, and lack of full control should not be underestimated, and this reflects the need for brand governance processes.

\section{Discussion}

The purpose of this paper was to examine how decision-makers (chair of the board and CEOs) of different types of NSOs govern their brand considering the role of stakeholders and 
social media in their brand governance processes. By examining the role of stakeholders, (including social media) in co-creating NSOs brand, we moved beyond traditional approaches of brand equity (i.e. which focus on end customers and their knowledge of the brand).

Size of NSOs matters when it comes to brand governance. This is not totally surprising, given that other government issues (e.g., standardisation, formalisation, performance, stakeholder management, funding sources) also differ according to levels of professionalization (Lang et al., 2018), and size (Bayle \& Robinson, 2007; Kikulis et al., 1995a, 1995b; Seippel, 2002). Hence, the relevance to reveal and explain differences in terms of this relatively underexplored concept 'brand governance' according to size. This also strengthens the argument that branding issues and brand governance are to be considered together with other governance issues. Thus, our findings empirically support the need to incorporate brand governance as an important component of NSOs' governance.

Small NSOs seem to behave quite differently when it comes to governing their brand. While they acknowledge the importance of brand, there is little they actually do in terms of management and governance of their brand. These small NSOs have little resources (financial and human) and as such may be more concerned about survival and their ability to deliver programs for key stakeholders (i.e. athletes, coaches, officials) rather than establishing a clear brand strategy. This is reflected in the operational role played by the board regarding brand management decisions. In contrast, medium, large, and very large NSOs have done research on their brand strength and relevance, and have procedures in place to actively govern their brand, reflective of the importance they place on their brand and its relevance to overall organizational strategy and performance. Medium and larger NSOs are very cognizant of their brand and are very conscious how they are perceived by external stakeholders. They also seem to be more 
influenced by stakeholders in terms of their brand management and governance, compared to small and very large NSOs. In other words, brand image seems to be an important issue for these NSOs but the way they seek input from their external environment to determine whether the image is aligned with the NSOs core brand identity needs further investigation. Although some NSOs indicate that they conduct brand research, we do not know the extent of the research and whether it is a periodic (e.g. annual) or a one-off (e.g. for rebranding) exercise. Further, NSOs use different types of communications with different types of stakeholders.

The results confirm the wide variety of stakeholders that NSOs are involved with (Ferkins \& Shilbury, 2015b; Parent et al., 2018). However, the purpose and regularity of these communications need further investigation. While medium and larger NSOs solicit some input from stakeholders regarding the governance of their brand (e.g., discussion of brand decision with external stakeholders), there is no operational involvement of stakeholders in brand management and governance. For example, having stakeholders on the board may assist with brand governance for NSOs. National sponsors may have strong expertise with branding and brand governance, hence NSOs can learn from them. However, the fact that we found no evidence for formalized communication channels related to brand governance does not exclude informal communication from taking place in the form of personal communication of the CEO with stakeholder representatives, which can actually take place in NSOs of all sizes. This should be further explored through interviews with leaders of various NSOs.

NSOs actively manage and govern their brand internally. By doing so, they avoid 'stakeownership' (Ferkins \& Shilbury, 2015b) and managers are more concerned about 'controlling' the communications output than engaging stakeholders with the brand. Yet, Merz et al. (2009) stated that brand literature has evolved from focusing on output (the product) to the 
conceptualisation of brands as social processes in which multiple interactions occur and multiple conversations among different stakeholders take place (Iglesias et al., 2013) in the co-creation of brand value. In the case of branding, co-creation expands to embrace other stakeholders than consumers or members of NSOs (Hatch \& Schultz, 2010). NSOs have yet to fully embrace such an approach as this would mean a loss of control as "the world outside defines the brand to a greater degree, sometimes in opposition to the desire of managers" (Hatch \& Schultz, 2010, p. $603)$.

The most important strengths (connectivity, control, and effectiveness) and challenges (negative brand impact, consistency, and control) of social media related to brand governance were consistent with previous research (Naraine \& Parent, 2017b). The issue of control seems important for NSOs as it appears as both a strength and a challenge. But controlling the brand in a new networked society where consumers have access to information is not possible nor is it encouraged (Abeza, O’Reilly, Finch, Séguin, \& Nadeau, 2018). New information technologies have given consumers much more access to information about the brands they use and consumers can now share their opinions with people that they have never met. Such reality is affecting the process of brand value creation and is calling into question the ways in which brands should interact with consumers (Ind, Iglesias, \& Schultz, 2013). As such, managers must accept that they may (are) losing control of their brands and embrace the opportunities (Abeza et al., 2018; Iglesias et al., 2013). This supports the need for organizations to consider brand governance as an essential part of their overall governance responsabilities.

\section{Theoritical Implications}

The potential for NSOs and stakeholders to co-create the brand is consistent with Merz et al.'s (2009) 'stakeholder-focus brand' era. While strategic brand management in this new era 
involves the managing of stakeholders and their relationships in co-creating the brand (Ferrand et al., 2012; Jones, 2005), the actions of stakeholders (internal and external, and/or primary and secondary) and other processes of strategic brand management must be in line with the vision, values, and mission of an organization to uphold brand consistency and contribute to brand equity. This, we argue is a governance issue, and our findings empirically support the need to incorporate brand governance as an important component of NSOs governance. As such, this study contributes to the literature on governance by including 'brand governance' as an important component in NSOs goal of building and nurturing their brand as a long-term strategic asset. Brand governance is an overarching concept that goes beyond managing the brand and into governance of the brand by setting a guiding direction for NSOs strategic brand management decisions. NSOs are encouraged to actively engage stakeholders and social media in this externally oriented activity. Most studies on brand governace have been conceptual in nature (Helms \& Jones, 2010; Ind \& Bjerke, 2007; Jones, 2005). This study examined brand governance empirically and contributes to the literature by providing insights on that brand governance is not yet strongly incorptated in the overall brand governance of NSOs, while demontrsating the need for it.

\section{Implications for NSOs}

While some larger NSOs seem to be more advanced in terms of governing their brand (i.e. brand research, brand documents, ensuring consistency with mission, vision, and values), our findings suggest that NSOs manage and govern their brand internally. Such an approach mirrors the traditional paradigm of brand management where product branding practices dedicate most resources to building the brand's outward image (Morrison \& Crane, 2007) through diverse communication initiatives. We suggest that NSOs are missing an opportunity to fully engage 
stakeholders (i.e., volunteers, government, suppliers, COC, athletes and their entourage, coaches, OTP, fans, print and social media, sponsors) in the process of brand co-creation strategies (Ferrand et al., 2012). Managing co-creations implies an approach to leadership that is open and transparent (Ind et al., 2013). This suggests that managers of NSOs should think about how to bring the experience of external stakeholders inside the organization to inform the brand and the decision-makers and managers who represent the brand. Stakeholders can be invited to help build NSO brands and in doing so, can 'live the brand' in a way that is similar to employees and members (athletes, coaches officials). This means managers need to accept that others may have insights and solutions that are worth considering and as such, co-creation must be considered with an open mind. As brands become more participative (Ind et al., 2013), decision-making processes must become more participative and collective. In other words, while recognizing the needs and desire of consumers remain an important aspect of brand building, it is no longer enough. NSOs need to incorporate stakeholders into all stages of brand thinking and implementation (Ind et al., 2013). However, such an approach has important governance implications for NSOs as this means sharing control of the brand with stakeholders (Ind \& Bjerke, 2007).

This notion of brand control for NSOs is exacerbated by the expanse of social media in the operational landscape. As the results suggest, NSOs seem confined to a basic paradigm of reporting, informing, and promotional (RIP) content production and communication, in line with Naraine and Parent's (2016a) assertion. However, this type of strategy is removed from harnessing influencers (Naraine \& Parent, 2016b) and brand anthropomorphism (Thompson et al., 2017) activities that are possible in the social space. Part of the explanation for this type of online behaviour is the struggle to evaluate social media from a strategic, multidimensional 
standpoint. The findings indicate that the NSOs do see value in social media; particularly medium and larger NSOs see the importance of being cognizant in how social media may impact their overall brand. Moreover, when asked whether NSOs communicate directly about their mission, vision, and values through social media, scores were decisively low. While this result is in line with Naraine and Parent (2016a), it speaks to the continual limited focus of how social media can be used for additional brand governance maintenance. The reality remains one in which NSOs are limited in their human and financial capacity, and also face resistance to change (Naraine \& Parent, 2017b). As such, social media has been adopted by NSOs, but only insofar as to exhibit relevance and currency to their stakeholders (Naraine \& Parent, 2017a). In this respect, social media is valued for its operational marketing capacity (Sanderson \& Yandle, 2015). Yet, the other dimensions of social media, including the ability to showcase an identity, build a reputation, and share with others suggests it can also be a beneficial tool for brand governance (cf. Kietzmann et al., 2011).

The overuse of social media only for RIP purposes is also concerning given that NSOs continue to espouse the great importance stakeholders have via social media as their digital voice is amplified and echoes (Parent et al., 2018). Social media, particularly in sport, is not a fad that is likely to dissipate; the number of stakeholders developing their social media personas and engaging in NSO networks is increasing (Naraine \& Parent, 2016b). Despite this recognition, NSOs appear to not be 'all-in' on social media, not using the medium to its full capacity. However, it is important to recognize that ascertaining whether social media was used to communicate NSOs mission, vision, and values cannot capture the notion of 'fit' with complete accuracy. That is, NSOs may disagree with Kietzmann et al.'s (2018) assertion that social media can actually be used in a manner separate from their current utilization vis-à-vis the RIP strategy. 
In summary, the finding support the notion that NSOs can gain a competitive advantage when they start incorporating brand governance in their overall governance practices.

\section{Future Research}

Given the relatively underexplored concept of brand governance, this study was exploratory in nature, establishing to what extent NSOs of various sizes are concerned with brand governance processes (or not). The study offered a better understanding to what extent stakeholders are involved in brand governance (or not), but the actual role of stakeholders in NSOs' governance needs further examination. This can be done through interviews with leaders (CEOs and board members) from various NSOs, as this will allow to supersede this first level of self-evaluation and deepen our understanding of brand governance in NSOs. Interviews should include aspects such as how NSOs perceive and incorporate brand governance in their overall governance practices, and these practices can support NSOs to gain competitive advantage. For example, is it 'better' to have the board of directors or the senior executive (CEO/Executive Director) govern the brand? In a similar vein, it would be worthwhile to compare the views of senior executives, who are professionals, with those of the Board of Directors, to ascertain potential differences in understanding of the brand governance concept and its processes. This could, for instance, help explain the degree to which NSOs involve (or not) their stakeholders and use (or not) social media while governing their brand. Interviews can also offer deeper insight which stakeholders, how (type of interaction and exchanged resources), and in which way (i.e., forms of communication) the interaction between NSOs and stakeholders can actually optimize brand governance in NSOs of all sizes.

The taxonomy of the NSOs for this study was based on capacity variables: budget and personnel (i.e., full time equivalents). While perhaps simplistic, it offered a first step for 
unpacking this relatively new concept of brand governance. The fact whether medium-sized and larger NSOs experience greater influence from stakeholders in their brand managers is related to seeking additional capacity, or because of their aspiration to capitalize on co-creating their brand governance processes, needs further exploration. Future research could also analyse brand governance practices from the perspective of different levels of professionalization (e.g., Chantelat, 2001; Clausen et al., 2018; Lang et al., 2018), including levels of effectiveness, performance, and so on.

Finally, it would be important to determine the extent to which our findings extend to NSOs in different countries, as well as to different levels of sports organizations (i.e., international, regional/state/provincial, and local).

\section{Conclusion}

This study explored how NSOs govern their brand and considered the role of stakeholders and social media their brand governance processes. The findings suggest that brand governance is absent in small NSOs, and in early stages of application by larger NSOs. For instance, brands are closely tied to mission/vision/values of NSOs which are developed at the highest level of the organization and must be implemented throughout the organization. We noted, however, that for the majority of NSOs managing their brand is of strategic importance, given that several procedures and process are already put in place to create brand equity. Brand strategy is discussed internally by all NSOs, while medium and large NSOs are more likely to experience some influence from external stakeholders.

Stakeholders are important for NSOs, but NSOs do not capitalize on their stakeholder relationships to co-create their brand. While there is no evidence that NSOs engage meaningfully with stakeholders to co-create their brand, NSOs do use various communication platforms 
including social media to build their brand. However, we need to learn more about the machanisms of interactions between NSOs and stakeholders as it pertains to brand governance. NSOs fear of losing control negatively impacts the true potential to strengthening their brand through social media. It is by loosening up some control that brand co-creation through social media can come to fruition. These decisions about brand co-creation require deeper engagement with stakeholders and social media. This needs to be laid out at the highest levels of the organizations, hence the need for brand governance.

\section{Acknowledgement}

The authors wish to thank the Social Sciences and Human Research Council of Canada as well as Sport Canada for their financial support of this project (\#435-2017-0247).

\section{References}

Abeza, G., O'Reilly, N., Finch, D., Séguin, B., \& Nadeau, J. (2018, October). The role of social media in the co-creation of value in relationship marketing: A multi-domain study. Journal of Strategic Marketing. 1-22. doi:10.1080/0965254X.2018.1540496

Bauer, H. H., Sauer, N. E., \& Schmitt, P. (2005). Customer-based brand equity in the team sport industry. European Journal of Marketing, 39(5/6), 496-513.

Bayle, E., \& Robinson, L. (2007). A framework for understanding the performance of national governing bodies of sport. European Sport Management Quarterly, 7(3), 249-268.

Bouchet, P., Hillairet, D., \& Bodet, G. (2013). Sport brands. London, UK: Routledge.

Canada Not-for-profit Corporations Act, S.C. 2009, c. 23 (2009). Retrieved from https://laws.justice.gc.ca/eng/acts/c-7.75/

Chantelat, P. (2001). La professionnalisation des organisations sportives: Nouveaux enjeux, nouveaux débats. [The professionalization of sport organizations: New issues and debates] Paris, France: L'Harmattan. 
Canadian Olympic Committee. (2013). Canadian Olympic Committee 2013 annual report. Retrieved from https://cdnolympic.files.wordpress.com/2014/06/coc_ar2013_en.pdf

Clarkson, M. B. E. (1995). A stakeholder framework for analyzing and evaluating corporate social performance. Academy of Management Review, 20(1), 92-117.

Clausen, J., Bayle, E., Giauque, D., Ruoranen, K., Lang, G., Nagel, S., ... Schlesinger, T. (2018). Drivers of and barriers to professionalization in international sport federations. Journal of Global Sport Management, 3(1), 37-60.

Ferkins, L., \& Shilbury, D. (2010). Developing board strategic capability in sport organisations: The national-regional governing relationship. Sport Management Review, 13(3), 235254.

Ferkins, L., \& Shilbury, D. (2015a). Board strategic balance: An emerging sport governance theory. Sport Management Review, 18(4), 489-500.

Ferkins, L., \& Shilbury, D. (2015b). The stakeholder dilemma in sport governance: Toward the notion of "stakeowner". Journal of Sport Management, 29(1), 93-108.

Ferrand, A., Chappelet, J. L., \& Séguin, B. (2012). Olympic marketing. London, UK: Routledge.

Ferrand, A., \& McCarthy, S. (2009). Marketing the sports organisations: Building networks and relationships. London, UK: Routledge.

Freeman, R. E. (1984). Strategic management: A stakeholder approach. Boston, MA: Pitman.

Girginov, V., Taks, M., Boucher, B., Martyn, S., Holman, M., \& Dixon, J. (2009). Canadian national sport organizations' use of the Web for relationship marketing in promoting sport participation. International Journal of Sport Communication, 2, 164-184. 
Gladden, J. M., \& Funk, D. C. (2002). Developing an understanding of brand associations in team sport: Empirical evidence from consumers of professional sport. Journal of Sport Management, 16(1), 54-81.

Gladden, J. M., \& Milne, G. R. (1999). Examining the importance of brand equity in professional sports. Sport Marketing Quarterly, 8(1), 21-30.

Gladden, J. M., Milne, G. R., \& Sutton, W. A. (1998). A conceptual framework for evaluating brand equity in division I college athletics. Journal of Sport Management, 12(1), 1-19.

Hall, M. H., Andrukow, A., Barr, C., Brock, K., de Wit, M., Embuldeniya, D., ... Vaillancourt, Y. (2003). The capacity to serve: A qualitative study of the challenges facing Canada's nonprofit and voluntary organizations. Toronto, ON: Canadian Centre for Philanthropy.

Hamm-Kerwin, S., \& Doherty, A. (2010). Intragroup conflict in nonprofit sport boards. Journal of Sport Management, 24(3), 245-271.

Harris, F., \& de Chernatony, L. (2001). Corporate branding and corporate brand performance. European Journal of Marketing, 35(3/4), 441-456.

Hatch, M. J., \& Schultz, M. (1997). Relations between organizational culture, identity and image. European Journal of Marketing, 31(5/6), 356-365.

Hatch, M. J., \& Schultz, M. (2010). Toward a theory of brand co-creation with implications for brand governance. Journal of Brand Management, 17(8), 590-604.

Helm, C., \& Jones, R. (2010). Extending the value chain - A conceptual framework for managing the governance of co-created brand equity. Journal of Brand Management, 17(8), 579-589.

Hoye, R., \& Cuskelly, G. (2003a). Board-executive relationships within voluntary sport organisations. Sport Management Review, 6(1), 53-73. 
Hoye, R., \& Cuskelly, G. (2003b). Board power and performance within voluntary sport organisations. European Sport Management Quarterly, 3(2), 103-119.

Hutchinson, M., \& Bennett, G. (2012). Core values brand building in sport: Stakeholder attitudes towards intercollegiate athletics and university brand congruency. Sport Management Review, 15(4), 434-447.

Iglesias, O., Ind, N., \& Alfaro, M. (2013). The organic view of the brand: A brand value cocreation model. Journal of Brand Management, 20(8), 670-688.

Ind, N. (2007). Living the brand: How to transform every member of your organization into a brand champion. London, UK: Kogan Page Publishers.

Ind, N., \& Bjerke, R. (2007). Branding governance: A participatory approach to the brand building process. Chichester, UK: Wiley.

Ind, N., Iglesias, O., \& Schultz, M. (2013). Building brands together: Emergence and outcomes of co-creation. California Management Review, 55(3), 5-26.

Inglis, S. (1997). Shared leadership in the governance of amateur sport: Perceptions of executive directors and volunteer board members. Avante, 3(1), 14-33.

Jones, R. (2005). Finding sources of brand value: Developing a stakeholder model of brand equity. Brand Management, 13(1), 10-32.

Keller, K. L. (2003). Strategic brand management: Building, measuring, and managing brand equity (2nd ed.). Upper Saddle River, NJ: Prentice Hall.

Kietzmann, J. H., Hermkens, K., McCarthy, I. P., \& Silvestre, B. S. (2011). Social media? Get serious! Understanding the functional building blocks of social media. Business Horizons, 54, 241-251. 
Kikulis, L. M., Slack, T., \& Hinings, C. R. (1995a). Sector specific patterns of change in organizational design change. Journal of Management Studies, 32(1), 67-100.

Kikulis, L. M., Slack, T., \& Hinings, C. R. (1995b). Toward an understanding of the role of agency and choice in the changing structure of Canada's national sport organizations. Journal of Sport Management, 9, 273-299.

Kowalczyk, S. J., \& Pawlish, M. J. (2002). Corporate branding through external perception of organizational culture. Corporate Reputation Review, 5(2/3), 159-174.

Krashinsky, S. (2018, May 15). Canada's amateur sport organizations step up their marketing game. The Globe and Mail. Retrieved from https://www.theglobeandmail.com/report-onbusiness/industry-news/marketing/canadas-amateur-sport-organizations-step-up-theirmarketing-game/article24797964/

Kumar, N. (2003). Kill a brand, keep a customer. Harvard Business Review, 81(12), 86-95.

Lang, G., Schlesinger, T., Lamprecht, M., Ruoranen, K., Klenk, C., Bayle, E., ... Nagel, S. (2018). Types of professionalization: Understanding contemporary organizational designs of Swiss national sport federations. Sport, Business and Management: An International Journal, 8(3), 298-316.

MacIntosh, E., \& Doherty, A. (2007). Extending the scope of organisational culture: The external perception of an internal phenomenon. Sport Management Review, 10(1), 45-64.

Merz, M., He, Y., \& Vargo, S. (2009). The evolving brand logic: A service-dominant logic perspective. Academy of Marketing Science Journal, 37(3), 328-344.

Morrison, S., \& Crane, F. G. (2007). Building the service brand by creating and managing an emotional brand experience. Journal of Brand Management, 14(5), 410-421. 
Naraine, M. L., \& Karg, A. (2019). Digital media in international sport: Engaging fans via social media and fantasy sports. In E. MacIntosh, G. Bravo, \& M. Li (Eds.), International sport management (pp. 315-331). Champaign, IL: Human Kinetics.

Naraine, M. L., \& Parent, M. M. (2016a). "Birds of a feather": An institutional approach to Canadian national sport organizations' social-media use. International Journal of Sport Communication, 9, 140-162.

Naraine, M. L., \& Parent, M. M. (2016b). Illuminating centralized users in the social media ego network of two national sport organizations. Journal of Sport Management, 30(1), 689701.

Naraine, M. L., \& Parent, M. M. (2017a). Examining social media adoption and change to the stakeholder communication paradigm in not-for-profit sport organizations. Journal of Amateur Sport, 3(2), 55-81.

Naraine, M. L., \& Parent, M.M. (2017b). This is how we do it: A qualitative approach to national sport organizations' social-media implementation. International Journal of Sport Communication, 10, 196-217.

Parent, M. M. (2016). Stakeholder perceptions on the democratic governance of major sports events. Sport Management Review, 9(4), 402-416.

Parent, M. M., Eskerud, L., \& Handstad, D. V. (2012). Brand creation in reoccurring sports events. Sport Management Review, 15(2), 145-159.

Parent, M. M., Naraine, M. L., \& Hoye, R. (2018). A new era for governance structures and processes in Canadian national sport organizations. Journal of Sport Management, 32(6), 555-566. 
Parent, M. M., \& Séguin, B. (2008). Toward a model of brand creation for international largescale sporting events: The impact of leadership, context, and nature of the event. Journal of Sport Management, 22(5), 526-549.

Richelieu, A. (2004). Building the brand equity of professional sports teams. In B. G. Pitts (Ed.), Sharing best practices in sport marketing (pp. 3-21). Morgantown, WV: FiT Publishing.

Richelieu, A., \& Pons, F. (2009). If brand equity matters, where is the brand strategy? A look at Canadian hockey teams in the NHL. International Journal of Sport Management and Marketing, 5(1/2), 162-182.

Sanderson, J., \& Yandle, C. (2015). Developing successful social media plans in sport organizations. Morgantown, WV: FiT Publishing.

Schultz, M., \& Ervolder, L. (1998). Culture, identity and image consultancy: Crossing boundaries between management, advertising, public relations and design. Corporate Reputation Review, 2(1), 29-50.

Séguin, B., \& Abeza, G. (2019). Olympic brand governance: Future research directions. In M. Winand, \& C. Anagnostopoulos (Eds), Research handbook on sport governance (pp. 368383). Cheltenham, UK: Edward Elgar Publishing.

Séguin, B., Richelieu, A., \& O’Reilly, N. (2008). Leveraging the Olympic brand through the reconciliation of corporate consumers brand perceptions. International Journal of Sport Management and Marketing, 3(1/2), 3-22.

Seippel, Ø. (2002). Volunteers and professionals in Norwegian sport organizations. International Journal of Voluntary and Nonprofit Organizations, 1(3), 253-270.

Slack, T., \& Hinings, C. R. (1992). Understanding change in national sport organizations: An integration of theoretical perspectives. Journal of Sport Management, 6(2), 114-132. 
Slack, T., \& Hinings, C. R. (1994). Institutional pressures and isomorphic change: An empirical test. Organization Studies, 15(6), 803-827.

Thompson, A-J., Martin, A. J., Gee, S., \& Geurin, A. N. (2017). Fans' perceptions of professional tennis events' social media presence: Interaction, insight, and brand anthropomorphism. Communication \& Sport, 5(5), 579-603.

Urde, M. (2003). Core value-based corporate brand building. Journal of Marketing, 37(7/8), 1017-1040.

Underwood, R., Bond, E., \& Baer, R. (2001). Building service brands via social identity: Lessons from the sports marketplace. Journal of Marketing Theory \& Practice, 9(1), 113.

Vargo, S., \& Lusch, R. (2004). Evolving to a new dominant logic for marketing. Journal of Marketing, 68(1), 1-17.

Vargo, S. L., \& Lusch, R. F. (2010). From repeat patronage to value co-creation in service ecosystems: A transcending conceptualization of relationship. Journal of Business Market Management, 4(4), 169-179.

Watkins, B. A. (2014). Revisiting the social identity-brand equity model: An application to professional sports. Journal of Sport Management, 28(4), 471-480.

Winand, M., Vos, S., Claessens, M., Thibaut, E., \& Scheerder, J. (2014). A unified model of non-profit sport organizations performance: perspectives from the literature. Managing Leisure, 19(2), 121-150.

Zaichkowsky, J. L. (2010). Strategies for distinctive brands. Journal of Brand Management, 17(8), 548-560. 
Figure 1: Brand Governance of NSOs and the Interrelationship with Stakeholders and Social Media: An Exploratory Model

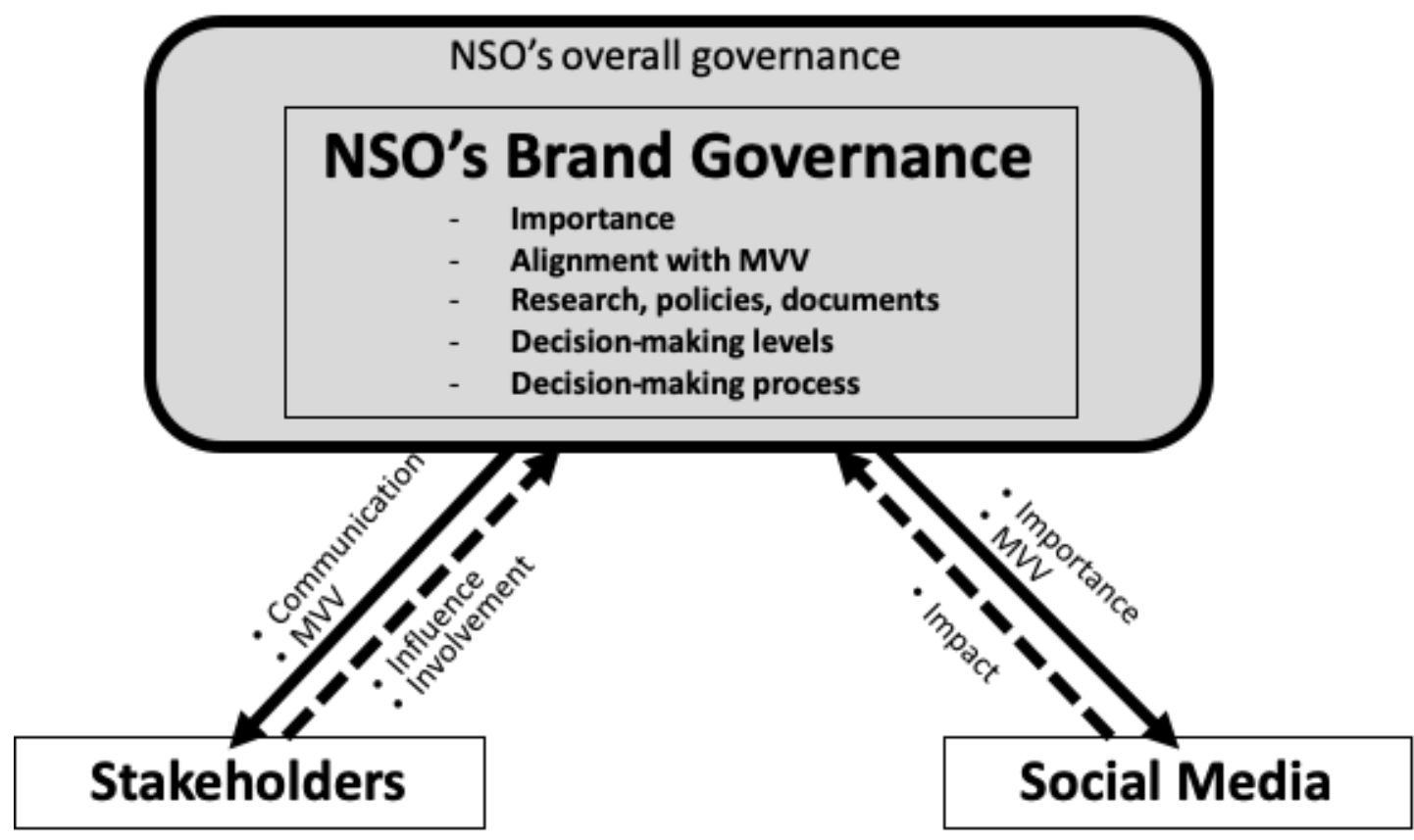

Note. Solid lines: represents how engagement of NSOs' decision makers with stakeholders and social media may affect their brand governance processes.

Dotted lines: represents how NSOs' decision makers perceive the effects of stakeholders and social media on their brand governance processes.

MVV = Mission, Vision, Values 
Table 1: Brand Governance within the Four Types of NSOs

\begin{tabular}{|c|c|c|c|c|c|c|c|}
\hline & & & & & & & \\
\hline & & $\begin{array}{c}\text { Overall } \\
\mathrm{n}=32\end{array}$ & $\begin{array}{l}\text { Small } \\
\mathrm{n}=7\end{array}$ & $\begin{array}{c}\text { Medium } \\
\mathrm{n}=15\end{array}$ & $\begin{array}{c}\text { Large } \\
\mathrm{n}=8\end{array}$ & $\begin{array}{c}\text { XLarge } \\
\mathrm{n}=2\end{array}$ & $\mathrm{p}$ \\
\hline Brand An Important Issue & $\begin{array}{c}M \\
(S D)\end{array}$ & $\begin{array}{l}4.09 \\
(0.89)\end{array}$ & $\begin{array}{c}3.57 \\
(1.27)\end{array}$ & $\begin{array}{c}4.4 \\
(0.51)\end{array}$ & $\begin{array}{l}4.13 \\
(0.99)\end{array}$ & $\begin{array}{c}3.5 \\
(0.71)\end{array}$ & 1.818 \\
\hline Brand aligned with MVV & (\% yes) & 91 & 71 & 93 & 100 & 100 & na \\
\hline Brand Research & (\% yes) & 56 & 14 & 67 & 63 & 100 & na \\
\hline Brand Document & (\% yes) & 40 & 0 & 39 & 63 & 100 & na \\
\hline Brand Policies \& Regulations & (\% yes) & 52 & 14 & 57 & 63 & 100 & na \\
\hline \multicolumn{8}{|l|}{ Brand Management Decisions } \\
\hline$C E O / E D$ & (\% yes) & 53 & 0 & 73 & 50 & 100 & na \\
\hline$B o D$ & (\% yes) & 34 & 71 & 27 & 25 & 0 & na \\
\hline Marketing Team & (\% yes) & 3 & 0 & 0 & 13 & 0 & na \\
\hline Other & (\% yes) & 9 & 29 & 0 & 13 & 0 & na \\
\hline \multicolumn{8}{|l|}{ Brand Strategy Discussions } \\
\hline Internally & $(\%$ yes $)$ & 97 & 86 & 100 & 100.00 & 100 & na \\
\hline External Stakeholders & (\% yes) & 55 & 17 & 67 & 63.00 & 50 & na \\
\hline $\begin{array}{l}\text { Image/reputation considered } \\
\text { when taking OD }\end{array}$ & $\begin{array}{c}M \\
(S D)\end{array}$ & $\begin{array}{c}3.81 \\
(1.18)\end{array}$ & $\begin{array}{l}2.71^{(\mathrm{a})} \\
(1.38)\end{array}$ & $\begin{array}{l}4.20^{(\mathrm{b})} \\
(1.01)\end{array}$ & $\begin{array}{c}3.88 \\
(0.84)\end{array}$ & $\begin{array}{c}4.5 \\
(0.71)\end{array}$ & $3.491^{*}$ \\
\hline
\end{tabular}

Note. $\mathrm{MVV}=$ Mission, Visions, Values; $\mathrm{CEO}=$ Chief Executive Officer; $\mathrm{ED}=$ Executive Director; $\mathrm{BoD}=\mathrm{Board}$ of Directors; $\mathrm{OD}=$ Operational Decisions; ${ }^{(a)}$ (b) are significantly different (post-hoc Tukey test); $M$ : means based on a 5-point Likert scale (from $1=$ not at all to $5=$ very important/always). 
Table 2: Interrelationship between Brand Governance of the NSOs and the Stakeholders according to the Four Types of NSOs

\begin{tabular}{lccccccc} 
& & Overall & Small & Medium & Large & XLarge & $\mathrm{p}$ \\
& & $\mathbf{n = 3 2}$ & $\mathrm{n}=7$ & $\mathrm{n}=15$ & $\mathrm{n}=8$ & $\mathrm{n}=2$ & \\
\hline SH communication varies & $(\%$ yes) & $\mathbf{9 7}$ & $86^{(1)}$ & 100 & 100 & 100 & na \\
SH communication fit MVV & $M$ & $\mathbf{3 . 9 1}$ & 3.14 & 4.13 & 4.00 & 4.50 & 2.275 \\
& $(S D)$ & $\mathbf{( 0 . 9 6 )}$ & $(1.57)$ & $(0.52)$ & $(0.76)$ & $(0.71)$ & \\
SH influence brand management & $M$ & $\mathbf{3 . 1 3}$ & $2.29^{(\mathrm{a})}$ & $3.53^{(\mathrm{b})}$ & 3.25 & 2.50 & $4.535^{*}$ \\
& $(S D)$ & $\mathbf{( 0 . 9 1 )}$ & $(1.11)$ & $(0.64)$ & $(0.71)$ & $(0.71)$ & \\
SH involved with brand management & $M$ & $\mathbf{2 . 4 4}$ & 1.86 & 2.80 & 2.38 & 2.00 & 2.314 \\
& $(S D)$ & $\mathbf{( 0 . 8 8 )}$ & $(0.90)$ & $(0.68)$ & $(0.92)$ & $(1.41)$ & \\
\hline
\end{tabular}

Note. $\mathrm{SH}=$ Stakeholders; MVV $=$ Mission, Vision, Values; ${ }^{(1)}=1$ response missing; ${ }^{*}=\mathrm{p}<.05 ;$ na $=$ not applicable; (a) (b) are significantly different (post-hoc Tukey test); $M$ : means based on a 5-point Likert scale ( $1=$ not at all to $5=$ always). 
Table 3: The Role of Social Media in Brand Governance according to the Four Types of NSOs

\begin{tabular}{lccccccc} 
& & Overall & Small & $\begin{array}{c}\text { Medium } \\
2\end{array}$ & Large & XLarge & $\mathrm{p}$ \\
& & & & & \\
& $\mathbf{n}=\mathbf{3 2}$ & $\mathrm{n}=7$ & $\mathrm{n}=15$ & $\mathrm{n}=8$ & $\mathrm{n}=2$ & \\
\hline SM important issue & $M$ & $\mathbf{4 . 6 6}$ & 4.29 & 4.87 & 4.63 & 4.50 & 2.835 \\
& $(S D)$ & $\mathbf{( 0 . 4 8 )}$ & $(0.49)$ & $(0.35)$ & $(0.52)$ & $(0.71)$ & \\
SM to communicate MVV & $M$ & $\mathbf{3 . 5 3}$ & 2.86 & 3.73 & 3.88 & 3.00 & 1.856 \\
& $(S D)$ & $\mathbf{( 1 . 0 2 )}$ & $(0.90)$ & $(0.88)$ & $(1.25)$ & 0.00 & \\
SM impacts brand & $M$ & $\mathbf{3 . 8 4}$ & $2.57^{(\mathrm{a})}$ & $4.40^{(\mathrm{b})}$ & $3.88^{(\mathrm{b})}$ & 4.00 & $9.241^{* * *}$ \\
& $(S D)$ & $\mathbf{( 1 . 0 2 )}$ & $(0.54)$ & $(0.63)$ & $(0.99)$ & $(1.41)$ &
\end{tabular}

Note. $\mathrm{SM}=$ Social Media; MVV $=$ Mission, Vision, Values; ${ }^{* * *}=\mathrm{p}<.00 ;{ }^{(a)}$ (b) are significantly different; $M$ : means based on a 5 -point Likert scale ( $1=$ not at all to $5=$ very important/always). 